\title{
Correction to: Influence of Orifice Position Deviations on Distribution Performance of Gravity-Type Liquid Distributor Analyzed Through Mathematical Pathway
}

\author{
Jinsheng Sun ${ }^{1} \cdot$ Zhiwei Zhang $^{1}$ - Chengtian Cui ${ }^{1}$ Tianpei $\mathrm{Li}^{1}$ · Sheng Fu${ }^{1}$
}

Published online: 9 June 2021

๑) Tianjin University and Springer-Verlag GmbH Germany, part of Springer Nature 2021

\section{Correction to: Transactions of Tianjin University https://doi.org/10.1007/s12209-017-0078-6}

Publisher's note Springer Nature remains neutral with regard to jurisdictional claims in published maps and institutional affiliations.

In the original publication of the article, the authorization or reference of Fig. 1 cited for describing the installation location of liquid distributor (pink) in column wasn't normatively provided. Considering that many literatures can provide information like Fig. 1, and the relationship between this picture and the contents can be negligible, Fig. 1 will be deleted. Meanwhile, the words "as shown in Fig. 1" in the first sentence of the introduction will also be deleted.

The original article can be found online at https://doi.org/10.1007/ s12209-017-0078-6.

Jinsheng Sun

jssun2006@vip.163.com

1 School of Chemical Engineering and Technology, Tianjin

University, Tianjin 300072, China 